\title{
Can Information Availability Increase Patient Compliance? Mitigating Uncertainty Perceptions in the Provider-Patient Relationship
}

\author{
Karoly Bozan \\ Idaho State University \\ bozakaro@isu.edu
}

\begin{abstract}
Patient compliance with provider directions is central to patients' well being, and non-compliance has been identified as a leading cause of increasing healthcare costs. While numerous factors may affect patient compliance, we investigate the mediating effect of patient health information availability on the relationship between perceived uncertainty and patients' motivation to comply with providers' orders. To understand how to mitigate perceived uncertainty, we extend the underlying principles of principal-agent theory-hidden information and hidden action-and propose three uncertainty-mitigating factors: perceived information asymmetry, fear of opportunism, and physician quality. The proposed structural model is empirically tested using data from 184 patients. Our model is supported, and the results provide an understanding of the process by which patients engage in their care through the support of information technology. We discuss the implications for understanding and facilitating the providerpatient relationship and its effect on patients' motivation to comply through the principal-agent perspective.
\end{abstract}

\section{Introduction}

Patient non-compliance with providers' orders is considered one of the major causes of low effectiveness of medical care [1,2] and increasing healthcare costs [3]. Further, research has shown that patient non-adherence contributes to a significant portion of admissions and readmissions [4-6] and is a source of ongoing frustration with doctors [7].

Several studies have investigated the potential underlying factors of non-adherence [3, 8-11], and close to 200 factors have been investigated [12]. Nevertheless, no factor has been identified as fully predictive and consistently related to patient compliance [13-14]. In our review of the literature, we found that uncertainty about the provider's approach is an essential driver of a patient's questioning the treatment and makes many patients reluctant to comply with the course of treatment. $[8,9,11,42,47$, 49]

To better understand the sources of patient uncertainty and, thus, to help to mitigate its effect on patient non-adherence, we examine this issue through the principal-agent perspective of agency theory. Although agency theory was originally developed for the employer-employee relationship [15], we use agency theory as it is understood in the information economics literature [16-19]. Using agency theory in this way fits our study, as the agency approach to uncertainty suggests that self-interested parties have incompatible goals, with hidden information and hidden actions. This approach holds true in any industry or socioeconomic systems in which information asymmetry and fear of opportunism exist in a transactional setting [20].

The principal-agent perspective has been extensively applied in the healthcare setting, in which patients are the principals who delegate the care delivery responsibility to providers (agents) in exchange for payment. This transaction takes place in the context of uncertainty due to the fact that patients cannot fully monitor the decision-making process, and the provider clearly has more information about the diagnosis and chosen course of treatment than does the patient. These circumstances led to the fundamental information problem of the provider-patient transaction-based relationship: (1) the hidden information-based diagnosis and treatment selection and (2) the hidden action that is a morally questionable approach to treating patients [16-17,21]. Patients often feel that the recommended treatments involve unnecessary medication or extended therapy so that providers may get reimbursed for unnecessary services.

Health economists have been evaluating such a possibility and have recommended regulations to limit such situations with outcome-based reimbursement vs. fee-for-service payments. However, the cost of monitoring the agent behavior in healthcare outweighs the benefit gained from it, leaving room for selfinterested decision making.

In this study, we investigate the sources of patients' perceived uncertainty and its effect on their motivation to comply with providers' decision on 
treatment. Further, we evaluate the impact of the availability of patient health information and patient educational material on patients' motivation to comply. We investigate the role of information systems in supporting the mitigation of uncertainty and in providing patient access to relevant information. Our recommendations may help providers to adopt certain features of existing electronic medical and health records systems to increase healthcare delivery effectiveness. Finally, we provide a foundation for regulations that may have an impact on health information system success in increasing patient compliance with providers' orders.

\section{Research Model and Hypotheses}

We propose a theoretical model and six hypotheses, as shown in Figure 1. Using our proposed model, we examine the sources of patients' perceived uncertainty and its direct and mediated impact on patients' motivation to comply with providers' orders. We propose that personal health information availability mediates the impact of perceived uncertainty on motivation to comply. We used previously collected qualitative data to identify constructs that either negatively or positively affect our proposed outcome variable, although we do recognize that other variables may affect patients' motivation to comply. We also conducted a thorough review of the literature related to the identified constructs and propose three sources of perceived uncertainty and one indirect mediating effect on motivation to comply. We base our arguments on principal-agent theory, which includes the principles of hidden information and hidden action as the basis for uncertainty and the degree of disbelief about the legitimacy of the ordered treatment.

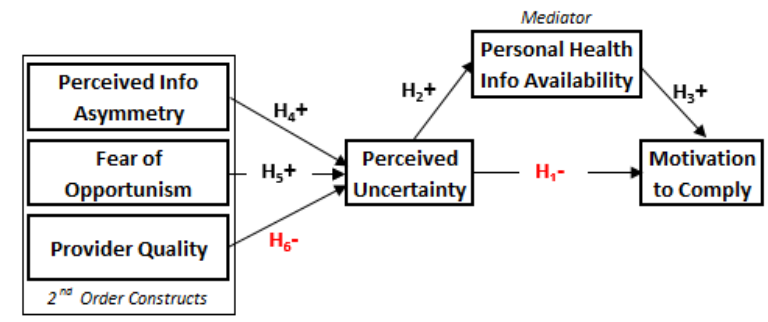

Figure 1. Proposed theoretical model

\subsection{Patient Uncertainty and Motivation to Comply}

Uncertainty, by definition, is the inability to accurately predict an outcome due to lack of perfect information or time [22]. The literature refers to uncertainty in the provider-patient interaction as uncertainty of the treatment's capability to improve patient's health [23]. In this study, we refer to patients' perceived uncertainty as the disbelief in providers' diagnosis and recommended treatment due to lack of perfect information and perceived divergence of interests. Because the provider collects payment for services, regardless of the outcome, patients may feel that, due to differing provider reimbursement methods, they do not receive optimal treatment [2425].

To better understand this phenomenon of uncertainty, including its sources, nature, and potential negative impact on patients' motivation to comply with providers' orders, we refer to the principal-agent perspective of agency theory. Uncertainty increases risk perception that influences patients' perceived decrease in the treatment success outcome [26]. Perceived risk is generally found to erode a relationship in a transactional context [27] and to negatively influence the receiving party's compliance [28]. Hence, we hypothesize:

H1: A higher degree of perceived uncertainty in providers' actions decreases the motivation to comply with the providers' orders.

Due to patients' very limited face-to-face time with their providers, they rely on additional healthrelated information, which is perceived to be useful if it is relevant, complete, easily understandable, and adequate [31]. When patients have questions about the diagnosis or treatment, they find that it is a lengthy and burdensome process to talk to the physician and often get charged additional visit fees. As a result, they may feel uncertain about the quality or quantity of information that their provider shared with them [30]. Therefore, patients gather information from external sources, which makes them feel empowered [29]. The information asymmetry between the provider and patient can be mitigated by the patient's acquiring additional health condition-specific information.

The high rate of electronic health and medical records adoption by providers show the capacity of and promise to reduce healthcare costs and diagnosis errors, while increase efficiency. Electronic health and medical records provide access to personal health information and relevant patient education material, but the effect of these records on treatment efficiency has not received sufficient attention. Although the majority of patients are not health literate, having access to their visit notes, diagnosis, lab results, and treatment decisions, if presented in a coherent manner, may increase their engagement in their care and adherence to provider decisions [32]. Patients who are concerned about the diagnosis and treatment decision are more likely to reach for additional health information, and once they increase their health 
literacy, they are more likely to comply with provider treatment decisions [33]. For the purposes of this study, we define personal health information availability as the proper access to relevant, reliable, adequate, and understandable information that increases patients' heath literacy related to their health condition. We concentrate on patient access to their diagnosis and results as well as relevant patient education material that may be provided through the provider's health information system. Therefore, we hypothesize the mediating effect of personal health information availability on the relationship between perceived uncertainty and patients' motivation to comply with providers' treatment orders.

H2: A higher degree of perceived uncertainty in providers' actions positively influences patients' demand for personal health information availability.

H3: A higher degree of personal health information availability positively influences patients' motivation to comply with the providers' orders.

\subsection{Uncertainty in Provider-Patient Relationship through Principal-Agent Perspective}

The imbalance of available information places the patient in a vulnerable position [43], which can be understood by the agent-principal perspective. This perspective has been applied in the healthcare setting to investigate the provider-patient relationship [3536]. As adopted from Pavlou et al. [37], the principalagent perspective is presented in Table 1, which presents the six requirements for the principal-agent theory to hold and includes the corresponding requirements for the provider-patient interaction.

Table 1. Application of the principal-agent perspective in provider-agent interaction

\begin{tabular}{|l|l|}
\hline \multicolumn{1}{|c|}{ Principal-Agent } & \multicolumn{1}{|c|}{ Provider-Patient Relationships } \\
\hline \multicolumn{1}{|c|}{$\begin{array}{l}\text { Principal } \\
\text { delegates } \\
\text { authority or } \\
\text { responsibility to } \\
\text { an agent who } \\
\text { acts on his or her } \\
\text { behalf. }\end{array}$} & $\begin{array}{l}\text { The patient (principal) delegates } \\
\text { responsibility to a provider (agent) } \\
\text { to deliver services to improve } \\
\text { patient's health in exchange for } \\
\text { payment. }\end{array}$ \\
\hline \multicolumn{2}{|c|}{ Divergence of Interests } \\
\hline $\begin{array}{l}\text { Principals and } \\
\text { agents have } \\
\text { different interests } \\
\text { and goals. }\end{array}$ & $\begin{array}{l}\text { The patient wants to receive } \\
\text { effective and high quality treatment } \\
\text { for the least amount of money. } \\
\text { Provider is motivated to receive as } \\
\text { much payment as possible for the }\end{array}$ \\
\hline
\end{tabular}

\begin{tabular}{|l|l|}
\hline \multicolumn{2}{|c|}{ Potential for Agent's Gainful Exchange } \\
\hline $\begin{array}{l}\text { Possibility for } \\
\text { agents to gain by } \\
\text { shirking } \\
\text { responsibility or } \\
\text { acting } \\
\text { opportunistically. }\end{array}$ & $\begin{array}{l}\text { The provider has the opportunity to } \\
\text { diagnose the patient in a way that } \\
\text { treatment choice would maximize } \\
\text { provider's benefit rather than } \\
\text { improve patient's health. }\end{array}$ \\
\hline \multicolumn{1}{|c|}{ Difficulty in Monitoring / Enforcing Human Action } \\
\hline $\begin{array}{l}\text { Principals cannot } \\
\text { easily monitor } \\
\text { agents and } \\
\text { enforce their } \\
\text { expected actions. }\end{array}$ & $\begin{array}{l}\text { The patient cannot easily monitor } \\
\text { whether provider has made a proper } \\
\text { or most appropriate diagnosis and } \\
\text { treatment choice. }\end{array}$ \\
\hline Agents Not Bearing the Consequences of their Actions \\
\hline $\begin{array}{l}\text { Agents act on } \\
\text { behalf of } \\
\text { principals who } \\
\text { own the assets } \\
\text { being managed. }\end{array}$ & $\begin{array}{l}\text { The provider has the freedom to } \\
\text { diagnose a patient based on available } \\
\text { information and choose an } \\
\text { appropriate treatment deemed } \\
\text { suitable by the provider. }\end{array}$ \\
\hline \multicolumn{2}{|c|}{ Temporal Duration } \\
\hline $\begin{array}{l}\text { There is a time } \\
\text { lag in which the } \\
\text { agent's actions } \\
\text { can be } \\
\text { manifested. }\end{array}$ & $\begin{array}{l}\text { It may take a considerable amount of } \\
\text { time before the effectiveness of } \\
\text { diagnosis and chosen treatment } \\
\text { effectiveness can be measured. } \\
\text { There are many variables involved, } \\
\text { and the responsibility of the provider } \\
\text { narrows with the time lag. }\end{array}$ \\
\hline
\end{tabular}

Mitigating uncertainty is highly dependent on trust, which has a rich literature in organizational behavior [27], information systems [38], social networks [39], buyer-seller relationships [40], economics [41], and doctor-patient relationships [42]. For the purposes of this study, we identify the sources of uncertainty and their mediating effect on patient motivation to comply with providers' orders. Hence, we purposely omit trust, as it is unrealistic to assume that a patient can build trust with a provider after a brief meeting, particularly with a patient's awareness of possible hidden information and hidden actions.

To identify the sources of perceived uncertainty, we follow the literature and apply the relevant constructs through the principal-agent perspective. The known gap in knowledge between provider and patients [35] provides information asymmetry [43]. During the short face-to-face meeting with the provider, patients may not receive sufficient information to fully understand and accept the diagnosis and recommended treatment. There is certainly little time to challenge the provider's findings due to the knowledge gap and often intimidating approach of providers [44]. Hence, we hypothesize: 
H4: A higher degree of information asymmetry between providers and patients increases patients' perceived uncertainty.

When the principal-agent goals are incompatible and the hired agent may act in his or her own benefit, the principal may feel that his or her transaction provides an opportunity for the agent to act opportunistically. Because the principal cannot monitor the agent's decisions and behavior, due to information asymmetry, opportunism may take place in the principal-agent transaction [45].

In the healthcare context, the provider may choose to diagnose the patient in a way that provides an opportunity for additional tests or medication that increases chargeable services and goods in addition to the necessary and adequate level, based on patients' condition [46]. We define fear of opportunism as the patient's concern that the provider acts opportunistically during their transaction. Angell [47] defined doctors as "double agents" who cannot be expected to "withhold beneficial care to save money for third-party payer." However, it is difficult to monitor what is beneficial and necessary. Because patients are vulnerable to unfair diagnosis and treatment choices due to a costly and cumbersome overview for compliance, this provides the grounds for hidden actions on behalf of the providers, which increases patients' uncertainty. Hence, we propose:

H5: A higher degree of fear of provider opportunism positively influences patients' perceived uncertainty.

In this research, we identified provider quality based on Jayanti's [48] constructs of empathy, communication, and competence. Thus, our evaluation goes beyond professional qualifications to involve the personal qualities of the provider as well. Patients' agreeing with providers' orders and complying with their treatment decision has been found to be positively correlated with physician empathy and communication [498]. Hence, we propose:

H6: Higher patient perception of provider quality negatively influences patients' perceived uncertainty.

\section{Research Methodology}

We selected the outpatient context for the provider-patient relationship to test the indicators and antecedents of perceived uncertainty and its effect on patients' intention to comply with providers' orders.

\subsection{Measurement Development and Survey Administration}

Measurement items were adopted from the literature and modified for the context of this study. All variables were measured indirectly by reflective, direct measurement items. We used a 5-point Likertscale that allowed respondents to express their level of agreement ( 1 = strongly disagree, $5=$ strongly agree $)$ with the measurement items. The pilot study was administered to family members and friends as recommended by Churchill [50]. Based on pilot respondents' feedback, face validity was reviewed and discussed by a group of experienced researchers. The final survey consisted of 41 measurement items (questions). Table 2 presents the measures and their sources from the literature.

Table 2. Structural Model Measurement Items

\begin{tabular}{|l|l|l|}
\hline Measured Variable & $\begin{array}{l}\text { No. of } \\
\text { Measures }\end{array}$ & $\begin{array}{l}\text { Supported by } \\
\text { Literature }\end{array}$ \\
\hline Intention to Comply & 5 & {$[82-83]$} \\
\hline Perceived Uncertainty & 4 & {$[84]$} \\
\hline $\begin{array}{l}\text { Perceived Information } \\
\text { Asymmetry }\end{array}$ & 4 & {$[37][78][79]$} \\
\hline $\begin{array}{l}\text { Personal Health Record } \\
\text { Quality }\end{array}$ & 16 & {$[80][31]$} \\
\hline Provider Quality & 12 & {$[38][48][81-82]$} \\
\hline Health Info. Availability & 4 & {$[32]$} \\
\hline
\end{tabular}

After revision of the questions, the final version was administered to respondents drawn from convenience and snowball sampling. Because most of us have been patients, we reached out to friends and asked them to complete the survey and to pass it on to others. We also used social media to promote the survey. A link to an online survey was provided, which included an explanation of the survey context and definitions of the variables, along with consent [51]. The data collection took place from May to August 2015, and we received 217 responses, of which 184 were fully completed.

\section{Data Analysis and Results}

Partial least squares (PLS) was used to validate and test our measurement and structural models, for which we used SmartPLS Statistical Software for Structural Equation Modeling (version 3.2.1 Windows 
64 bit). The PLS statistical method, a componentbased latent structural equation modeling technique, provides more flexibility in terms of sample size and residual distribution [52-54].

\subsection{Measurement Validation}

Internal consistency exceeded 0.90 and was considered adequate for all principal constructs. We tested for construct validity through convergent (measures that should be related are, indeed, related) and discriminant (measures that should not be related are, indeed, not related) validity checks. The correlations among all constructs were below the 0.90 threshold, but related to an extent, and almost all statistically significant at the $p<0.05$ and $p<0.01$ levels. The square root of average variance extracted (AVE) was greater than that of any other crosscorrelations, and AVEs were greater than the 0.5 threshold, indicating that the principal constructs capture higher construct-related variance than errorrelated variance. We also performed principal component factor analysis, which showed that all items loaded on their corresponding constructs and with higher factor loadings than cross-loadings. The confirmatory factor analysis confirmed that items loaded to their principal constructs with clear loading patterns.

We tested for common method bias that may occur in self-report questionnaires due to something external to the measures. Bias can occur when one factor accounts for most of the variance due to item construction, item order, audience, scale used, and so forth [55]. As recommended by Podsakoff et al. [55], we employed Harman's single factor test, using exploratory factor analysis as widely used in the literature [56-60]. We received nearly equal variance loadings across the factors; therefore, this test revealed no indication of common method bias. The previously performed correlation among constructs did not reveal an extreme correlation $(>0.90)$, as the highest construct correlation was 0.74 . We also tested for partial correlations, as suggested by Podsakoff et al. [55], whereby we added the highest loaded factor into the PLS model as another control factor. Because none of the dependent variables increased significantly, no common method bias was indicated using the partial correlation method, either.

\subsection{Control Variables}

We chose five control variables from the literature and had limited missing values returned for these control variables, which we handled through the mean imputation method [61]. We performed a complete control variable analysis prior to our research model analysis. Four control variables (gender, age, income, and health knowledge) had a significant relationship with one or more of the endogenous variables and were included in the final structural model to ensure that their effect was accounted for. Although their effect is statistically significant, they had limited effect on the structural model's endogenous variables, which we measured through change in coefficient of determinants with and without the control variables $\left(\Delta \mathrm{R}^{2}<0.1\right)$.

\subsection{Structural Model Test}

The structural model was tested against the hypotheses through path coefficients, statistical significance, and $R$-squared value. Path coefficients measure the strength of the relationship between the independent and dependent variables, while the $R$ squared values indicate the predictive power of the model [62]. A nonparametric bootstrapping technique was used to calculate the $t$-statistics values in SmartPLS to test for statistical significance of the path coefficients [63-64]. We used the full sample to test the six hypotheses that we developed. The standardized PLS path coefficients, $R^{2}$, total and mediated effects, and control variables involved in testing the structural model are shown in Figure 2.

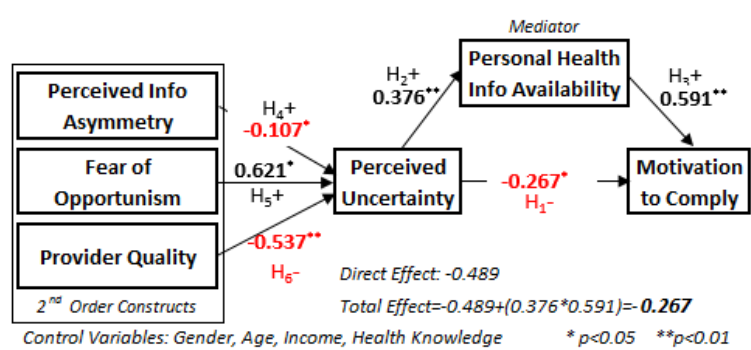

Figure 2. Path coefficients in the structural model

The standardized regression coefficients are generated first, followed by bootstrapping. Resampling with replacement at least 1,000 times is necessary for valid $t$-values, as suggested by Chin et al. [53]. $R$-squared $\left(R^{2}\right)$ values are reported for endogenous construct, as suggested Hulland [65].

As hypothesized, perceived uncertainty has a significant negative direct effect on motivation to comply $(b=-0.267, p<0.05)$ and supported H1. Perceived uncertainty also has a significant and relatively strong positive effect on personal health information availability $(b=0.376, p<0.05)$, explains 21 percent of its variance, and supports H2. Personal health information availability has a significant positive effect on motivation to comply $(b=0.591, p$ $<0.01$ ), which explains $36 \%$ of its variance and supports H3. 
The indicators of perceived uncertainty explained 48 percent of its variance. Unexpectedly, the perceived information asymmetry has a relatively week but significant negative effect on perceived information asymmetry $(b=-0.107, p<0.05)$ and does not support H4. Fear of opportunism has a strong significant positive $(b=0.621, p<0.05)$ effect on perceived uncertainty and confirms H5. As hypothesized, physician quality $(b=-0.537, p<0.01)$ showed a strong negative, significant relationship with perceived uncertainty and validated H6.

\subsection{Mediation Analysis}

Mediation occurs when a specific intervention influences an outcome and takes on a temporal and causal relationship. Mediation analysis may help to determine a more successful and cost-effective approach when developed using a proper prior theory and within the appropriate context.

When a predictor variable's significant effect on the outcome variable weakens through the introduction of a third variable, the mediator, an indirect or mediated effect is supported [66]. Full or complete mediation exists when the significant effect between the predictor and outcome variables become zero by adding the mediator variable. If the effect or relationship is reduced in size, partial mediation exists [67].

To test the mediating effect of personal health information availability, we followed Baron and Kenny's [66] test for mediation. We directly linked the perceived uncertainty construct to motivation to comply and removed the personal health information availability construct. The relationship between perceived uncertainty and motivation to comply showed a significant negative effect $(b=-0.489, p<$ 0.05). Once the personal health information availability construct was added back to the model, the effect decreased to $b=-0.267$. Following Baron and Kenny (1986), we performed bootstrapping for the valid $t$-value. We captured the mediator path coefficients $\left(b_{1}=0.376, b_{2}=0.591\right)$ and standard errors $\left(\mathrm{SE}_{1}=0.0736, \quad \mathrm{SE}_{1}=0.0813\right)$ from perceived uncertainty to personal health information availability and, from there, to the motivation to comply. We used a free Sobel Test Calculator for the Significance of Mediation [68] and received a Sobel test statistic of 4.179 , of which the absolute value is greater than 1.96 $(p<0.05)$. This revealed that personal health information availability partially mediates perceived uncertainty's effect on motivation to comply, as the direct effect between perceived uncertainty and motivation to comply decreased when the mediator was added in the integrative model [66].
Combining all this information, we can conclude that, of the -0.489 unit difference in motivation to comply that is attributable to a unit difference in perceived uncertainty, 0.222 of it is the result of the mediator effect of personal health information availability, which increases health literacy, which, in turn, increases motivation to comply with providers' order. The remaining -0.267 unit difference is direct, spurious, or attributable to other indirect effects not explicitly modeled [69].

\section{Discussion}

In this study, we examined the sources of perceived uncertainty and its effect on motivation to comply with providers' orders through the principal-agent perspective. We also investigated the mediating effect of personal health information availability. Using the PLS method, we developed a structural model and six hypotheses, which were empirically validated with 184 respondents who provided their input on the latent variables that we measured.

This study has several key findings with meaningful theoretical and practical implications. We formally proposed that the process of diagnosing symptoms, identifying course of treatments, and ordering self-delivered care should be viewed as agency relationships, whereby the proposed principalagent perspective applies in the provider-patient transaction process. The hidden information and action principles of the principal-agent perspective helped us to identify the sources of perceived uncertainty. This understanding can be applied to the mitigation of perceived uncertainly to achieve better patient motivation to comply. The mediator of personal health information availability also may be used to help reduce the two underlying fundamental agency problems.

This paper's primary contribution is to introduce personal health information availability as a key mediating variable in a model, which incorporates the agent-principal perspective, that explains patient motivation to comply with providers' orders. Patients' compliance has a great impact on the health of patients and on healthcare costs. Studies that examine the provider-patient relationship through a principal-agent perspective are driven by health economics principles developed by Mitnick and Ross's [70, 77] relational and institutions-based incentives-driven approach. We add to the patient-provider relationship literature by testing the precursors of perceived uncertainty in healthcare, which is a precursor to patient motivation to comply with providers' orders. These relationships have been overlooked in the literature, as information availability has been limited to the Internet [8] or face- 
to-face provider-patient communication [71]. With widely available and patient-accessible patient portals and education materials accessible or given at the time of provider visits, it is important to evaluate the transparent personal health records' and patients' health-related information's impact on patient compliance intention.

Studies that attempt to explain patient adherence [72-76] without an understating of the mediating role of personal health information availability, and its precursors and nature, likely result in incomplete and potentially misleading theories. In this study, we identified three factors-perceived information asymmetry, fear of opportunism, and provider quality-that may potentially mitigate perceived uncertainty by helping to uncover the hidden actions and hidden information.

We identified and described, on a more granular level, the process that develops and potentially mitigates perceived uncertainty and the mediator that facilitates patient motivation to comply. We proposed fear of opportunism and information asymmetry as factors in the agent-principal perspective, and this study is the first to use these constructs as indicators of perceived uncertainty in healthcare. The third variable, provider quality, has been studied as a latent variable in other studies [8] but has not been previously used as an indicator of perceived uncertainty.

The strong positive effect $(b=0.621, p<0.05)$ of fear of opportunism on perceived uncertainty is driven by patients who believe that doctors act in their own interests when adding chargeable services or products. Educating such patients during and after their visit, by providing proper access to relevant and understandable information related to their personal health condition, may greatly reduce patients' uncertainty about the recommended treatment and increase the motivation to comply with the ordered treatment.

The unexpected negative effect of perceived information asymmetry $(b=-0.107, p<0.05)$ may be due to the fact that patients often feel "lost" after talking to the doctor and blame themselves for not fully understanding what the doctor told them. In that case, they believe that the doctor is right and decrease their uncertainty about the diagnosis and treatment decision. We recommend to increase the health literacy by providing access to personal health information and relevant educational material.

\section{Limitations and Future Directions}

The principal-agent perspective has been developed and widely used in understanding the employer-employee relationship. We indicated the six key theoretical requirements that must be satisfied in the patient-provider service transaction approach, but this perspective will require further research to confirm its fit in the patient-provider context.

We excluded the possible moderating relationship of a "second opinion," which is a major factor in terms of reducing uncertainty. Although this option is freely available to any patient, most patients, due to the additional cost and time involved, do not take advantage of this for less complicated healthcare needs. An extension of this study could be an evaluation of whether providers consider the possibility of other professionals' viewing their decision and the extent to which it limits their possible opportunism. This could take place the monitoring of agent behavior for compliance and fairness. Furthermore, engaging in multiple doctor visits may develop a level of comfort in the patient if previous treatment plans were effective and successful. It may be worthwhile to introduce the moderating effect of "second-opinions" and multiple doctor visits into our proposed model.

The use of snowball sampling helped with the response rate and resulted in low-cost data collection. It could, however, have introduced bias into the sample responses, as many respondents referred another respondent to complete the survey, thereby limiting the generalizability of the findings.

\section{Conclusion}

In this study, we found that patient utilization of electronic health and medical records, which provides patient insight into provider decisions, coupled with provider-supplied relevant educational material, may potentially reduce perceived uncertainty and increase patients' motivation to comply with providers' orders. We recommended the use of health information technology to possibly increase patient compliance.

\section{References}

[1] Horne R., Representation of medication and treatment: advances in theory and measurements, In: Petrie R, Weinlan J, eds. Perceptions of Health and Illness: Current Research and Applications, London: Harwood Academic, 1997, pp. 155-188.

[2] Haynes, R.B., McKibbon,.. KA, Kanani, R., Brouwers, M.C., Oliver, T., Interventions to Assist Patients to Follow Prescriptions for Medications, Oxford: The Cochrane Collaboration. 1997.

[3] Iuga, A.O., and McGuire M.J., "Adherence and Health Care Costs", Risk Management and Healthcare Policy, 7, 2014, pp. 35-44. 
[4] Morris, L.S., Schulz, R.M., "Patient compliance: an overview", Journal of Clinical Pharmacy \& Therapeutics, 17(5), 1992, pp. 283-295.

[5] Donovan, J.L., Blake, D.R., "Patient non-compliance: deviance or reasoned decision-making?", Social Science and Medicine, 34(5), 1992, pp. 507-513.

[6] Donovan, J.L., "Patient decision making. The missing ingredient in compliance research", International Journal of Technology Assessment in Health Care, 11(3), 1995, pp. 443-445.

[7] Melnikow, J., Kiefe, C., "Patient compliance and medical research: issues in methodology", Journal of General Internal Medicine, 9(2), 1994, pp. 96-105.

[8] Laugesen, J., Khaled, H., and Yufei, Y., "The Impact of Internet Health Information on Patient Compliance: A Research Model and an Empirical Study." Ed. Gunther Eysenbach. Journal of Medical Internet Research, 17(6), 2015: e143. PMC. Web. 6 June 2016.

[9] Horne, R., Beliefs and adherence to treatment: the challenge for research and clinical practice, In: Halligan P., Aylward M., ed. The power of belief. Oxford: Oxford University Press, 2006, pp. 115-36.

[10] Horne, R., Weinman, J., Hankins, M., "The beliefs about medicines questionnaire: the development and evaluation of a new method for assessing the cognitive representation of medication", Psychology and Health, 14(1), 1999, pp. 1-24.

[11] Sjolander, M., Eriksson, M., and Glader, E.L., "The Association between Patients' Beliefs about Medicines and Adherence to Drug Treatment after Stroke: A CrossSectional Questionnaire Survey", BMJ Open, 2013, 3(9), e003551.

[12] Vermeire, E., Hearnshaw, H., Van Royen P., and Denekens J., "Patient adherence to treatment: three decades of research. A comprehensive review", Journal of Clinical Pharmacy and Therapeutics, 26,(5), 2001, pp. 331-342.

[13] Anon, Working Party from Compliance to Concordance. Achieving Shared Goals in Medicine Taking, Royal Pharmaceutical Society of Great Britain, London, 1997.

[14] Donovan, J.L., "Patient decision making. The missing ingredient in compliance research", International Journal of Technology Assessment in Health Care, 11(3), 1995, pp. 443-455.

[15] Berle, A. A., and Means, G. C., The Modern Corporation and Private Property, MacMillan Publishing, New York, 1932.

[16] Akerlof, G., "The Market for Lemons: Quality Uncertainty and the Market Mechanism," Quarterly Journal of Economics (84:3), 1970, pp. 488-500.
[17] Arrow, K. J. "Uncertainty and the Welfare Economics of Medical Care," American Economic Review (53:5), 1963, pp. 941-973.

[18] Rothschild, M., and Stiglitz, J. E., "Equilibrium in Competitive Insurance Markets: An Essay on the Economics of Imperfect Information," Quarterly Journal of Economics, 90(4), 1976, pp. 629-649.

[19] Spence, M., "Job Market Signaling,” Quarterly Journal of Economics, 87(3), 1973, pp. 355-374.

[20] Milgrom, P., and Roberts, J., Economics, Organization and Management, Prentice Hall, Upper Saddle River, NJ, 1992.

[21] Jensen, M., and Meckling, W. H., "The Theory of the Firm: Managerial Behavior, Agency Costs and Ownership Structure", Journal of Financial Economics, 3(4), 1972, pp. 305-360.

[22] Pfeffer, J., and Salancik, G., The External Control of Organizations: A Resource Dependence Perspective, Harper Row, New York, 1978.

[23] Kasper, J., Geiger, F., Freiberger, S., Schmidt, A., "Decision-related uncertainties perceived by people with cancer--modelling the subject of shared decision making", Psychooncology, 17(1), 2008, pp. 42-48.

[24] Newhouse, J.P., "Why Is There a Quality Chasm?" Health Affairs, 21(4), 2002, pp. 13-25.

[25] Rosenthal, M.B., and Frank, R.G., "What is the empirical basis for paying for quality in health care?" Medical Care Research Review, 63(2), 2006, pp. 135157.

[26] Chiles, T. H., and McMackin, J. F., "Integrating Variable Risk Preference, Trust, and Transaction Cost Economics", Academy of Management Review 21(1), 1996, pp. 73-99.

[27] Rousseau, D. M., Sitkin, S.B., Burt, R.S., and Camerer, C., "Not So Different After All: A Cross-Discipline View of Trust," Academy of Management Review, 23(3), 1998, pp. 393-404.

[28] Pavlou, P.A., "Consumer Acceptance of Electronic Commerce: Integrating Trust and Risk with the Technology Acceptance Model", International Journal of Electronic Commerce, 7(3), 2003, pp. 101-134.

[29] Broom, A., "Virtually healthy: the impact of internet use on disease experience and the doctor-patient relationship", Qualitative Health Research, 15(3), 2005, pp. 325-345.

[30] Wensing, M., "Evidence-Based Patient Empowerment", Quality in Health Care, 9(4), 2000, pp. 200-201. 
[31] Zahedi, F., Song, J., "Dynamics of trust revision: using health infomediaries", Journal of Management Information Systems, 24(4), 2008, pp. 225-248.

[32] Koh, H., Brach, C., Harris, L.M., and Parchman, M.L., "A Proposed 'Health Literate Care Model Would Constitute A Systems Approach to Improving Patients' Engagement in Care", Health Affairs, 2013, 32(2), pp. 357-367.

[33] Zhang, N.J., Terry, A., McHorney, C.A., "Impact of health literacy on medication adherence. A systematic review and meta-analysis", Annals of Pharmacotherapy, 48(6), 2014, pp. 741-751.

[35] Vick, S., Scott, A., "Agency in health care. Examining patients' preferences for attributes of the doctor-patient relationship", Journal of Health Economics, 17(5), 1998, pp. 587-605.

[36] Xie, B., Dilts, D.M., Shor, M., "The physician-patient relationship: the impact of patient-obtained medical information", Health Economics, 15(8), 2006, pp. 813-833.

[37] Pavlou, P., Liang, H., Xue, Y., "Understanding and mitigating uncertainty in online exchange relationships: A principal-agent perspective", MIS Quarterly, 31(1), 2007, pp. 105-136.

[38] McKnight, D.H., Choudhury, V., and Kacmar, C., "Developing and Validating Trust Measures for ECommerce: An Integrative Typology," Information Systems Research, 13(3), 2002, pp. 334-359.

[39] Gambetta, D. "Can We Trust Trust?" in Trust: Making and Breaking Cooperative Relations, D. Gambetta (ed.), Basil Blackwell, Oxford, England, 1988, pp. 213-237.

[40] Pavlou, P.A., and Gefen, D. "Building Effective Online Marketplaces with Institution-based Trust", Information Systems Research, 15(1), 2004, pp. 37-59.

[41] Williamson, O.E. "Calculativeness, Trust, and Economic Organization", Journal of Law and Economics, 36(1), 1993, pp. 453-486.

[42] Wroth, T.H., Pathman, D.E., "Primary medication adherence in a rural population: the role of the patientphysician relationship and satisfaction with care", The Journal of the American Board of Family Medicine, 19(5), 2006, pp. 478-486.

[43] Johnson, G.L., Ramaprasad, A., "Patient-physician relationships in the information age", Marketing Health Services, 20(1), 2000, pp. 20-7.

[44] Kronish, I.M., Leventhal, H. and Horowitz, C.R., "Understanding minority patients' beliefs about hypertension to reduce gaps in communication between patients and clinicians", The Journal of Clinical Hypertension, 14(1), 2012, pp. 38-44.

[45] Eisenhardt, K. "Agency Theory: An Assessment and
Review," Academy of Management Review 14(1), 1989, pp. 57-74.

[46] McGrath, J., "Overcharging the uninsured in hospitals: shifting a greater share of uncompensated medical care costs to the federal government", Quinnipiac Law Review 26, 2007, pp. 173-211.

[47] Angell M., "The doctor as double agent", Kennedy Institute of Ethics Journal, 3(3), 1993, pp. 279-286.

[48] Jayanti, R.K., Whipple, T.W., "Like me ... like me not: the role of physician likability on service evaluations", The Journal of Marketing Theory and Practice, 16(1), 2008, pp. 79-86.

[49] Vermeire,. E, Hearnshaw, H., Van Royen, P., Denekens, J., "Patient adherence to treatment: three decades of research. A comprehensive review", Journal of Clinical Pharmacy and Therapeutics, 26(5), 2001, pp. 331-42.

[50] Churchill, G., "A Paradigm for Developing Better Measures of Marketing Constructs," Journal of Marketing Research, 16(1), 1979, pp. 64-73.

[51] Kelley, K., Clark, B., Brown V., Sitzia, J., "Good practice in the conduct and reporting of survey research", International Journal for Quality in Health Care, 15(3), 2003, pp. 261-266.

[52] Anderson, J.C., Gerbing, D.W., "Structural Equation Modeling in Practice: A Review and Recommended TwoStep Approach”, Psychological Bulletin, 103(3), 1988, pp. 411-423.

[53] Chin, W.W., Marcolin, B.L., Newsted, P.R., “A partial least squares latent variable modeling approach for measuring interaction effects: Results from a Monte Carlo simulation study and an electronic mail adoption study", Information Systems Research, 14(2), 2003, pp. 189-217.

[54] Chin, W.W., "Issues and opinion on structural equation modeling”, MIS Quarterly, 22(1), 1998, pp. 7-16.

[55] Podsakoff, P.M., MacKenzie, S.B., Lee, J-Y., and Podsakoff, N. P. "Common Method Biases in Behavioral Research: A Critical Review of the Literature and Recommended Remedies," Journal of Applied Psychology, 88(5), 2003, pp. 879-903.

[56] Andersson, L. M., \& Bateman, T. S., "Cynicism in the workplace: Some causes and effects", Journal of Organizational Behavior, 18(5), 1997, pp. 449- 469.

[57] Aulakh, P.S., \& Gencturk, E. F., "International principal-agent relationships-control, governance and performance", Industrial Marketing Management, 29(6), 2000, pp. 521-538.

[58] Greene, C. N., \& Organ, D. W., "An evaluation of causal models linking the received role with job satisfaction", Administrative Science Quarterly, 18(1), 1973, 
pp. 95-103.

[59] Organ, D. W., \& Greene, C. N., "The effects of formalization on professional involvement: A compensatory process approach", Administrative Science Quarterly, 26(2), 1981, pp. 237-252.

[60] Schriesheim, C. A., "The similarity of individualdirected and group directed leader behavior descriptions", Academy of Management Journal, 22(2), 1979, pp. 345355.

[61] Hair JF, Black WC, Babin BJ, Anderson RE. Multivariate Data Analysis. Upper Saddle River, NJ: Prentice Hall; 2010.

[62] Barclay, D., Higgins, C., Thomson, R., "The partial least squares approach to causal modeling, personal computer adoption and use as an illustration", Technology Studies, 2(2), 1995, pp. 285-309.

[63] Efron, B., and Tibshirani, R. J., An Introduction to the Bootstrap, Chapman Hall: New York. 1993.

[64] Davison, A. C., and Hinkley, D. V., Bootstrap Methods and Their Application, Cambridge University Press: Cambridge. 1997.

[65] Hulland, J., "Use of Partial Least Squares (PLS) in strategic management research: A review of four recent studies", Strategic Management Journal, 20(2), 1999, pp. 195-204.

[66] Baron, R. M., \& Kenny, D. A., "The moderatormediator variable distinction in social psychological research: conceptual, strategic, and statistical considerations", Journal of Personality and Social Psychology, 51(6), 1986, pp. 1173-1182.

[67] Kenny, D. A., \& Judd, C. M., „Power anomalies in testing mediation", Psychological Science, 25(2), 2014, pp. 334-339.

[68] Soper, D.S., Sobel Test Calculator for the Significance of Mediation [Software]. Available from http://www.danielsoper.com/statcalc Accessed May 2016.

[69] Hayes, A.F., Preacher, K.J., \& Myers, T.A., "Mediation and the estimation of indirect effects in political communication research", In Bucy E. P., \& Holbert, R.L. (Eds), Sourcebook for political communication research: Methods, measures, and analytical techniques. (p. 434-465). New York: Routledge. 2011.

[70] Ross, S.A. "The economic theory of agency: The principal's problem". American Economic Review 62(2), 1973, pp. 134-139.

[71] Smith, P.C., Stepan, A., Valdmanis, V., Verheyen, P., "Principal-agent problems in health care systems: an international perspective", Health Policy, 41(1), 1997, pp. 37-60.
[72] Gordis, L., "General concepts for use of markers in clinical trials", Controlled Clinical Trials, 5(4), 1984, pp. 481-487.

[73] Farmer, K.C., "Methods for measuring and monitoring medication regimen adherence in clinical trials and clinical practice". Clinical Therapeutics. 21(6), 1999, pp.10741090.

[74] Liu, H., Golin, C.E., Miller, L.G., et al. "A comparison study of multiple measures of adherence to HIV protease inhibitors", Annals of Internal Medicine, 134(10), 2001, pp. 968-77.

[75] Garber, M.C., Nau, D.P., Erickson, S.R., et al. "The concordance of self-report with other measures of medication adherence: a summary of the literature", Medical Care, 42(7), 2004, pp. 649-52.

[76] Lee, J., Grace, K.A., Foster, T.G., "How Should We Measure Medication Adherence in Clinical Trials and Practice?" Therapeutics and Clinical Risk Management, 3(4), 2007, pp. 685-690.

[77] Mitnick, B.M., "Fiduciary rationality and public policy: The theory of agency and some consequences. Paper presented at the 1973 Annual Meeting of the American Political Science Association", New Orleans, LA. In Proceedings of the APSA, 1973, (formerly available from Xerox University Microfilms and, later, UMI Serials).

[78] Dunk, A.S., "The effect of budget emphasis and information asymmetry on the relation between budgetary participation and slack", Accounting Review, 68(2), 1993, pp. 400-410.

[79] Mishra, D.P., Heide, J.B., and Cort, S.G., "Information Asymmetry and Levels of Agency Relationships", Journal of Marketing Research, (35:3), 1998, pp. 277-295.

[80] Luo, X., "Trust Production and Privacy Concerns on the Internet: A Framework Based on Relationship Marketing and Social Exchange Theory", Industrial Marketing Management, 31(2), 2002, pp. 111-118.

[81] Kim, S.S., Kaplowit, S., Johnston, M.V., "The effects of physician empathy on patient satisfaction and compliance", Evaluation \& the Health Profession, 27(3), 2004, pp. 237-251.

[82] Hausman, A., "Modeling the Patient-Physician Service Encounter: Improving Patient Outcomes", Journal of the Academy of Marketing Science, 32(4), 2004, pp. 403-417.

[83] Ajzen, I., "The Theory of Planned Behavior," Organizational Behavior and Human Decision Processes 50(2), 1991, pp. 179-211.

[84] Torkzadeh, G., and Dhillon, G., "Measuring Factors that Influence the Success of Internet Commerce", Information Systems Research, 13(2), 2002, pp. 187-204. 